\title{
Wind Resource Potential Assessment and Implication for Climate Change Mitigation: The Case of Bale Zone, South Eastern Ethiopia
}

\author{
Mekuria Tefera $^{1} \quad$ Kassahun Ture $^{2}$ \\ 1.Department of Environmental Science, Wollega University \\ 2. Department of Physics, Addis Ababa University
}

\begin{abstract}
Wind power assessments as well as forecast of wind energy production potential are key issues in the wind energy industry. One of the necessary conditions for the development of wind power generation is to choose the optimal site. Alternative energy plays a great role for climate change mitigation, environmental protection and sustainable development. The objective of this study was to assess the distribution of wind resource based on WRF (Weather Research and Forecasting) model and its implication on climate change mitigation in Bale zone, south eastern Ethiopia. In this study, one year wind speed and wind direction at 6- hour intervals at a height of 10, 50 and 100 $\mathrm{m}$ were used. The data source is National Centers for Environmental Prediction (NCEP). In addition observational wind speed and wind direction data from National Meteorological Agency (NMA) of Ethiopia from ground based stations were used. The analysis result of the NCEP and NMA data by downscaling the model to $20 \mathrm{~km}$ by $20 \mathrm{~km}$ spatial resolution enabled to map the wind resource potential sites of Bale Zone applicable for wind mill installation. This study showed that most of the Bale zone areas have significant wind power potential to augment its current power generation. The analysis result revealed that wind resource potential is high during summer than winter season. Have a potential of installed 10,329MW wind capacity in Bale zone. If this potential wind resource will installed, so far environment as an estimation of about more than 5 thousand hectare of forest land per year would be preserved, and subsequently, equivalent amount of about 66,294 of $\mathrm{CO}_{2}$ would be stored per year.
\end{abstract}

Keywords: Wind speed; Wind direction; Wind power; WRF model; Bale zone

DOI: $10.7176 / \mathrm{JETP} / 11-1-01$

Publication date: January $31^{\text {st }} 2021$

\section{INTRODUCTION}

Wind power, as an alternative clean energy source, supports environmental sustainability and possibly provides part of the solution to our energy insecurity problem (Pryor et al., 2011). Increasing the value of wind generation through the improvement of the performance of prediction systems is one of the priorities for wind energy research in the coming years (Karimiotakis et al., 2004). From the point of view of wind energy, the most striking characteristic of the wind resource is its variability. Wind is highly variable, both geographically and temporally. Furthermore, this variability persists over a very wide range of scales, both in space and time. The application of numerical weather prediction (NWP) models for the simulation of wind conditions in a given area is one of important methods. Mesoscale NWP model are essential to the forecast process (Ma et al., 2009). One of the main advantages of WRF modeling for wind resource assessment is creating of wind maps, generating of 'virtual' wind climates, and to assist in generation of synthesized long term data sets by combining observations and WRF. Since accurate assessment of local wind resources is vital for the planning and the management of wind farms, where in-situ measurements are scarce and expensive, the validated mesoscale wind field simulations can provide a suitable alternative dataset. Growing interest in harvesting wind energy requires the development of reliable methodology for estimating the wind resources. In this study, we propose a methodology for the wind resource and site assessment studies at the Mesoscale level using numerical simulations and in-situ metrological data. The aim of this work is to assess wind resource potential sites of Bale zone, Ethiopia and its implication for mitigation of climate change. We have downscaled the model in a special resolution of $20 \mathrm{~km}$ by $20 \mathrm{~km}$ in the area of interest to map areas according to their wind resource potential. Despite the course special resolution of the model, we are able to identify wind resource potential regions of the zone. The paper is divided into the following sections. Next, we will see the materials and methods. In this section description of the study site, the WRF model, the data used and the methodology are explained in greater detail. Section 3 presents results and discussion. Finally conclusion and recommendations are given in section 4.

\section{MATERIALS AND METHODS}

\subsection{Study Area Descriptions}

Bale zone is the second largest zone of Oromia regional state of Ethiopia (Fig 1). It has total area of $63,555 \mathrm{~km}^{2}$ and covers $17.5 \%$ of the total area of the region. The zone has 18 districts, 33 towns, 349 rural villages. The altitude range is $300 \mathrm{~m}$ to $4389 \mathrm{~m}$ above sea level. The energy share from electricity is $10 \%$ while $90 \%$ is from traditional 
source such as fire wood, charcoal, kerosene, dung, crop residue based on the report of Bale Zone Finance and Economic Development Office (2013).

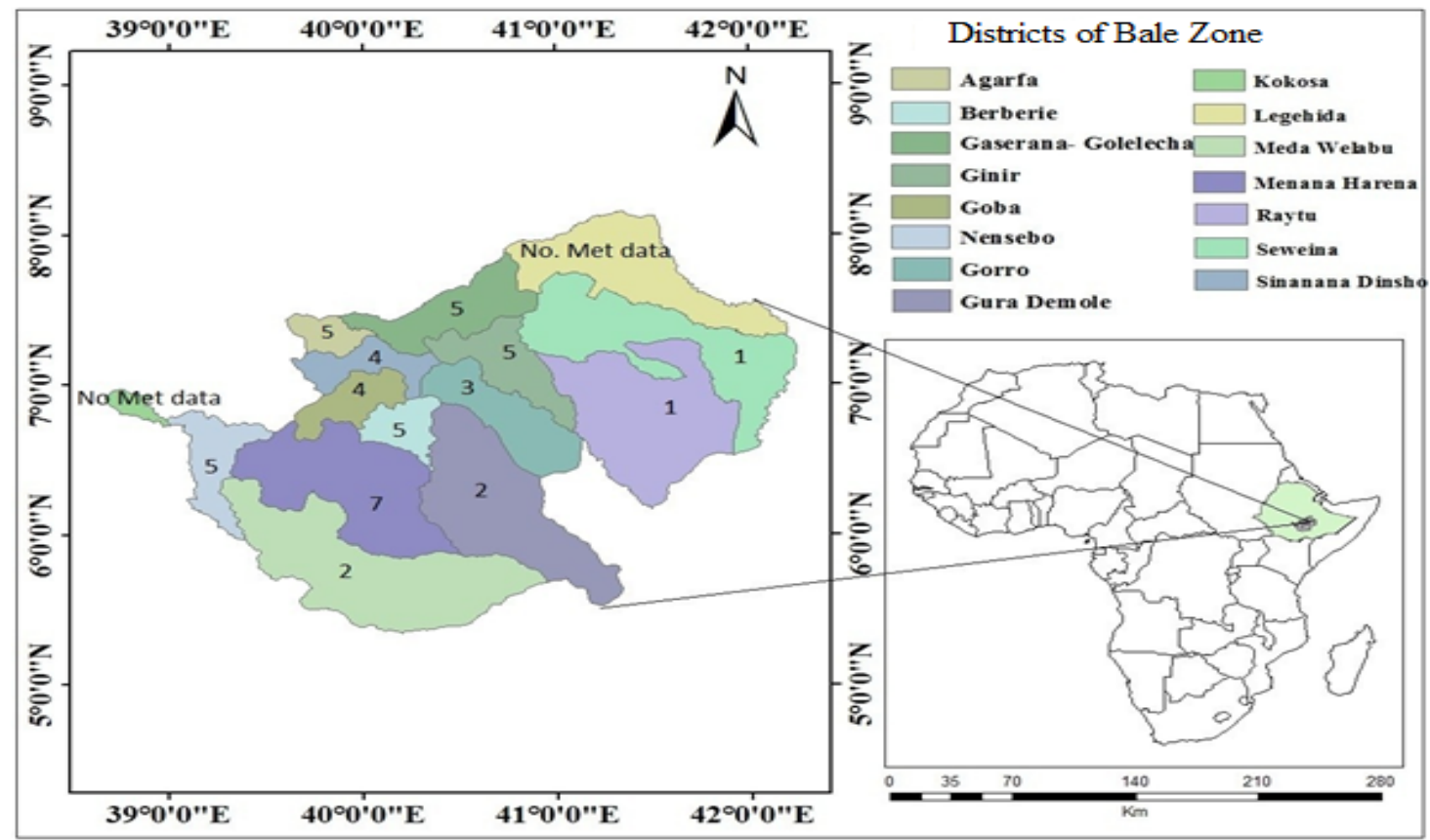

Fig.1 Geograpical map of bale zone with its districs (Numbers 1-7 show wind energy resource potentials of the districts, No Met data, indicates districts with no merological data)

Bale zone climate is highly variable from district to district. The annual average temperature of $17.5^{\circ} \mathrm{c}$, maximum annual temperature $32^{\circ} \mathrm{c}$ and minimum annual temperature $3.5^{\circ} \mathrm{c}$ and receives $550 \mathrm{~mm}-1200 \mathrm{~mm}$ amount of annual rainfall. The zone is characterized by a great diversity of thermal zones as a result of its wide range of altitude extent. It has classified as follows, Temperate 14.93\%, Subtropical 21.53\%, and Tropical $63.53 \%$ (BZFEDO, 2013).

\subsection{Methodology}

\subsubsection{Model description}

The study is based on the Weather Research and Forecasting Model (WRF, version 3.5), aired in September 2013 (Skamarock et al., 2008). WRF is a limited area meteorological model used for weather forecasting and climatic purposes. It employs an Eulerian mass-coordinate solver with a non-hydrostatic approach, and a terrain following Eta-coordinate system in the vertical. It is a state-of-the-art mesoscale model used in a variety of studies (Clifford et al., 2011; T. Haghroosta et al., 2014; J. J. Gómez-Navarro et al., 2015; P. Jimenez et al., 2013; F. J. SantosAlamillos., 2013) among others. The WRF model is a numerical weather prediction system for both research and operational forecasting purposes. The Weather Research and Forecast (WRF) model parameters are often used to represent the interaction between different scales in the process of model calculation. Using microphysics, short wave radiation and atmospheric long wave radiation, cumulus parameterization, boundary layer, and a physical parameterization scheme, the WRF model improves simulation results. In this study, the model used NCEP global 30-s topographic data and NCEP/NCAR (National Center for Atmospheric Research) reanalysis data as initial and lateral boundary conditions. These advanced models have the potential to improve the modeling of the wind flow, particularly in complex terrain. Low computation time to produce forecasts, and as a consequence, they update frequently their outputs.

\subsubsection{Data description}

Two kinds of data were used. One is observational ground data from Ethiopian National Meteorology head office, Addis Ababa, and the other is simulated data from NCAR by WRF model. The differences between the observed and simulated results were analyzed to see whether the Weather Research and Forecasting (WRF) model is able to capture the wind power resource of this location. In this study, wind speed and wind direction data at 6-hour intervals and average 1 year (2010) observations at a vertical height of 10, 50 and $100 \mathrm{~m}$ were used. To assess the wind power density of 1 year trend using the WRF model through dynamical downscaling, National Centers for Environmental Prediction (NCEP) Final (FNL) Operational Global Analysis data was used to verify the results. The data required are wind speed and vertical wind profile speed. These data are available on $0.5^{\circ} \times 0.5^{\circ}$ grids prepared operationally every six hours. 


\subsection{Methods}

The statistical analyses of the local distributions of wind speed and wind direction on Bale zone were laid for each $20 \mathrm{~km}$ by $20 \mathrm{~km}$ special resolution. Later, the wind speed and wind direction distribution maps were constructed. From the map areas of similar wind speed are categorized in one group. The average air density was evaluated from the respective elevations and the average wind power density was estimated for the winter and summer seasons. To assess its magnitude, the average value was thus estimated using the standard deviation of the wind speed normalized by the average wind speed. Finally, the energy yield and the capacity factor from the model data were calculated. Wind speed at turbine hub-height at 50 and $100 \mathrm{~m}$ is estimated by extrapolating the wind speed from a known height (at $10 \mathrm{~m}$ ) using the power-law relationship of Eqn1.

To estimate wind speed at turbine hub-height, it is common practice to extrapolate the wind speed from a known height (usually $10 \mathrm{~m}$ ) using the following power-law relationship:

$U(z)=\operatorname{Ur}\left(\frac{z}{z_{r}}\right)^{\alpha} \ldots \ldots \ldots \ldots \ldots \ldots \ldots \ldots 1$

Where $U r$ is the reference (or measured) wind speed at a given height, $z_{r} . U(z)$ is the estimated wind speed at height $z$, and $\boldsymbol{\alpha}$ is the shear exponent and can be approximated by the Eqn 2 as stated by (Manwell et al., 2009). According to them the installed capacity per $\mathrm{km}^{2}$ at height $100 \mathrm{~m}$ is $5 \mathrm{MW}$.

$$
\alpha=0.096 \log Z+0.016(\log Z)^{2}+0.24 \ldots \ldots \ldots \ldots \ldots \ldots . . \ldots \ldots
$$

According to (Antonio c. et al., 1997) these formulations should be restricted to a height of $200 \mathrm{~m}$; above this height the wind speed can be assumed to be constant.

Then to estimate the vertical profile of wind power densities across the Bale zone wind speed distributions at 50 and $100 \mathrm{~m}$ were used. These vertical heights are key levels as most of the wind turbine hub heights are planted around those levels. The wind power density is the energy yield proportional to the area swept by the turbine blade, air density and the velocity cubed. It is given by Eqn3.

$\frac{P}{A}=\frac{1}{2} \rho v^{3}$ ..3

Where, $\rho$ is the average density,

$P$ is the Power,

$A$ is the area, and

$V$ is the wind speed.

The special distribution of the density was calculated at $50 \mathrm{~m}$ and $100 \mathrm{~m}$ model levels, based on the temperature, pressure and mixing ratio (moisture effect) meteorological parameters, using the ideal gas law. Eqn.4 was used to calculate the moist air density. Dry area density is used in the standard calculations. However to account the density variations due to moisture which can affect the wind power density calculations the moisture effects included. The temperature, pressure and mixing ratio were first extracted from the WRF model at the two levels specified above and the density was calculated using Eqn 4. Finally, the wind power density was estimated using equation 3 .

Where, $\rho$ is the average density,

$$
\rho=\frac{P}{R T}\left(\frac{1+w}{1+1.6078 w}\right) \ldots \ldots \ldots . . . .4
$$

$\mathrm{P}$ is the pressure,

$\mathrm{T}$ is the temperature,

$\mathrm{W}$ is the mixing ratio of the universal gas constant.

\section{Results and discussion}

\subsection{Average wind speed, wind direction and wind energy distribution}

Based on the WRF model output and statistical analysis of ten year metrological data, districts are classified from super to marginal wind potential. The areas are labeled as shown in Fig.1 and Table1. However, four of wind energy resource potential districts from super to good be chosen. The ratings of the districts are made according to the classification by (Frank, 2014) and (Dennis E., 2007) as shown in table 2. Daily mean wind speed, wind direction distribution curves of these four districts of the zone are as shown in Fig.2 (A to D). In addition curves of monthly mean wind speed and wind power density of Rayitu, Madawalabu and Robe district are depicted in Fig.3 (A to C) and wind speed is also shown in Fig. 4 (A to C). Fig 2.A and Fig.3.A, shows the distribution of wind speed and direction of class1. Rayitu district is in this category. The blue bars are frequency of the wind speed and the red one shows wind direction. The average wind speed lies between 3 and $8 \mathrm{~ms}^{-1}$. Days in the first half segment of the graph are winter time (October to February) while the second half days are for summer (April to August). The magnitude of wind speed in the area is high and extremely variable during summer season than the winter season. The average wind speed is $V_{m}=6 \mathrm{~m} \mathrm{~s}^{-1}$ for the summer season and $2.25 \mathrm{~m} \mathrm{~s}^{-1}$ for the winter season.

From direction distribution Fig.5.A, east wind and southwest wind play the main role. The main role is played by east wind in winter half years of the Northern Hemisphere and South or Southwest in summer half year of the 
Northern Hemisphere. This indicates significant characteristics of monsoon climate (McKnight, et al., 2000) and (Ritter, et al., 2006)

Table1. Wind potential classification at $10 \mathrm{~m}$

\begin{tabular}{|c|c|c|c|c|}
\hline Rating & Wind power class & $\begin{array}{l}\text { Wind Power density at } 10 \mathrm{~m} \\
\mathrm{~W} / \mathrm{m}^{2}\end{array}$ & $\begin{array}{l}\text { Average wind } \\
\text { Speed at } 10 \mathrm{~m} / \mathrm{s}\end{array}$ & Name of districts in similar class \\
\hline 1 & Super & 196 & 5.05 & $\begin{array}{l}\text { Dawekachen, Rayitu and } \\
\text { Sewena }\end{array}$ \\
\hline 2 & Outstanding & 117 & 4.25 & Beltu and Madawalabu. \\
\hline 3 & Excellent & 94 & 3.95 & Delosebro, Gololcha, and Sinana \\
\hline 4 & Good & 43 & 3.05 & $\begin{array}{l}\text { Ginnir, Robe, Goba and } \\
\text { Daweserer }\end{array}$ \\
\hline 5 & Fair & 13 & 2 & Agarfa,Dinsho, Haro and Goro \\
\hline 6 & Marginal & 5 & 1.5 & Goro, and Dalomena \\
\hline 7 & Poor & 1.5 & 1 & Angetu, Direshekhusen, \\
\hline
\end{tabular}

In class 2 (see Fig. 2 B), the wind speed lies between 2.5 and $7 \mathrm{~m} \mathrm{~s}^{-1}$. Beltu and Madawalabu districts are in this class as shown in Table 1. Similarly, Fig.2.B is for Madawalabu district. Seen from the analysis result, there is rich wind resource around this area. In this site too, the average wind speed is not highly variable and the wind direction is more stable than the other area. The annual average model wind speed is $\mathrm{V}_{\mathrm{m}}=5 \mathrm{~m} \mathrm{~s}^{-1}$ at the height of $2 \mathrm{~m}$. Almost similar to that of the first super class, wind speed is higher from April to September. And also the curves of monthly mean wind speed and wind power density Fig. 3B shows the same result. The average wind direction is almost played main role east wind in winter half year of the Northern Hemisphere and southwest wind in summer half year of the Northern Hemisphere as almost similar with the first super wind class.

And also as shown Fig. 4B from direction distribution Northeast wind and Southwest wind play the main role. The wind speed distributions shows that summer have good wind distributions. In summer season the average wind direction is almost east wind but in winter the direction of the wind is southwest. Fig: 2.D shows the wind speed and direction for Robe. The wind speed lies between 1 and $5 \mathrm{~ms}-1$ this is categorized under class 4 . Districts in this class are Robe, Goba and Daweserer. In these areas wind speed is highly variable. But the wind direction is more variable in winter season than the summer season.

Similarly, Robe is in class 4, category. As Robe city (found in Sinana district) is closer to inland, significant change can been seen in wind speed statistics. High wind occurs from February to May which is almost different from others. For other areas have high wind and occur from April to August. This is because of geographical seasonal climate variability of the area (Jowder F., 2009) and (Ashenafi A. et al., 2008) also found a large variability from one location to the other and also from season to season at any fixed location. It is highly variable, both spatially and temporally and this variability exists over a very wide range of scales. This variability is dependent on the location and weather conditions of the area. Small-scale variation is dictated by factors such as ratio of land to water, terrain, etc.

As seen from direction distribution East wind plays the main role, with Characteristics of monsoon climate which cause a seasonal change in wind direction (McKnight, et al., 2000) (Fig. 2.D) and Fig. 3C. The wind speed lies between 1 and $5 \mathrm{~m} / \mathrm{s}$. In this areas wind speed is highly variable in summer season than the winter season. The average model wind speed is $\mathrm{V}_{\mathrm{m}}=3.25 \mathrm{~m} \mathrm{~s}^{-1}$ for the winter season and $2 \mathrm{~m} \mathrm{~s}^{-1}$ for the summer season.

The rainy season is often called the monsoon in Robe because it is associated with a change in the predominant wind direction; northeast winds prevail during the dry season and westerly to southwesterly winds during the rains. 

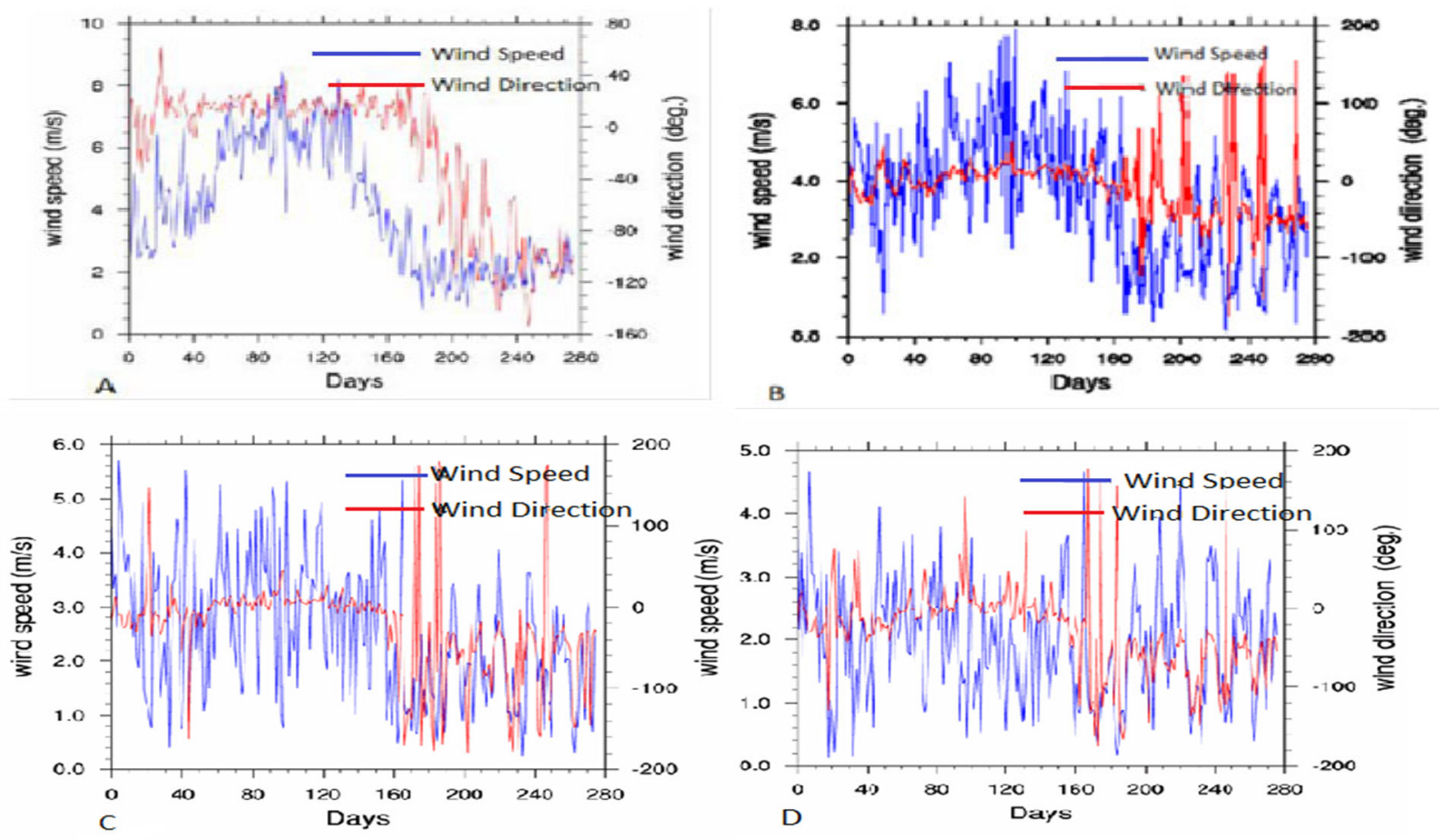

Fig.2: Daily Wind speed (blue bars) and wind direction (red bars) distribution curves of (A) Rayitu, (B) Madawalabu, (C) Meliyu and (D) Robe for the year 2010 from WRF model.

Madda Wlabu
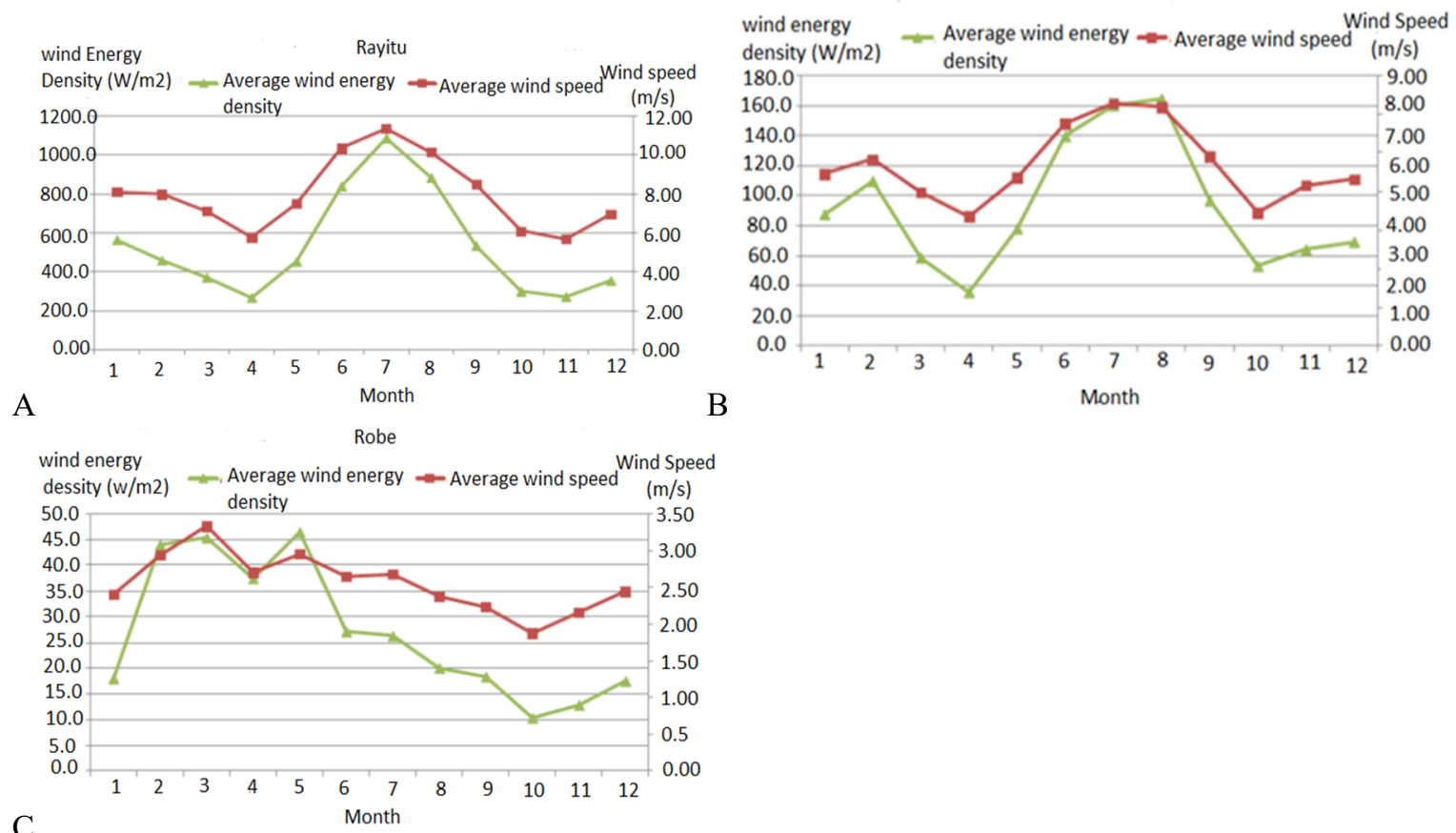

Fig.3 Curves of monthly mean wind speed and wind power density of (A) Rayitu, (B) Madawalabu, (C) Robe for the year 2010 from WRF model. 

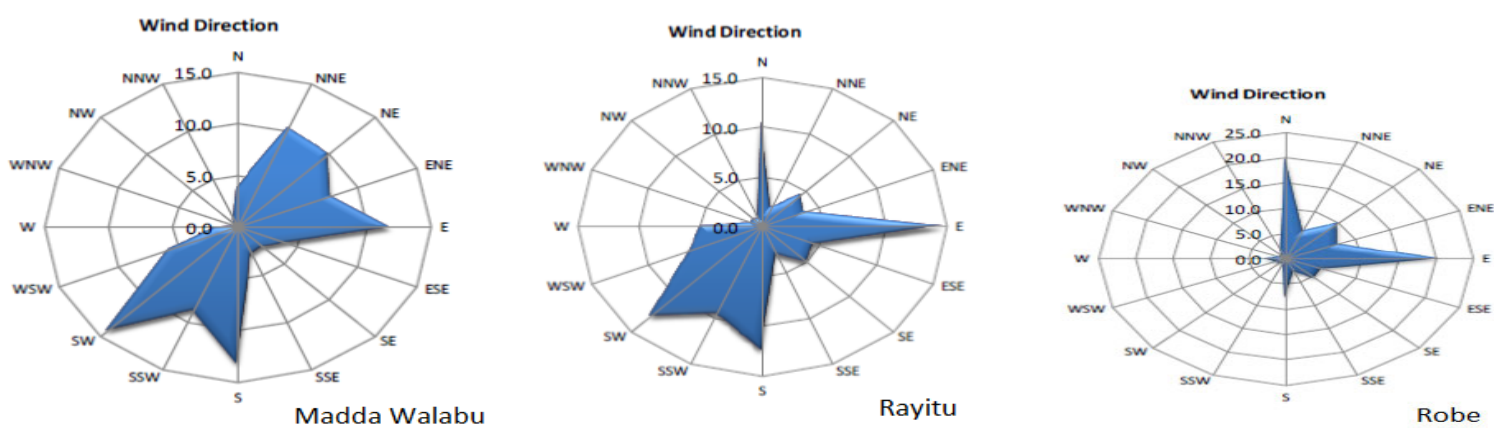

Fig 4. Direction distribution of wind speed of (A) Rayitu, (B) Madawalabu and (C) Robe for the year 2010 from WRF Model.

\subsection{Vertical profile of wind speed}

Bale zone east plain region mainly Dawekachen, Rayitu, Sewena, Beltu and Madawalabu has richest wind energy resource. Strong wind power under the alternative influence of North- east trade wind zone and Southwest monsoon zone. Hence it's richest in wind energy resource reserve in Bale zone. Mean wind speed of Bale zone in east is higher in the west and southwest. In a similar study country has enormous potential, wind energy (Oumer, 2013) and (Derbew, 2013). Therefore it meets requirements for assessing macro wind energy in most area over the Bale zone.

Vertical Profile of wind Speed

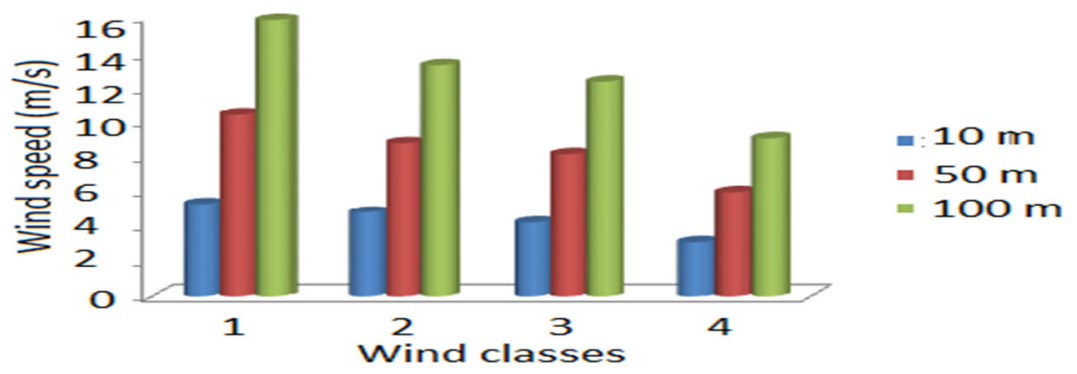

Fig5. Good to super wind potential classification at 10,50 and $100 \mathrm{~m}$.

The wind speed at 10,50 and $100 \mathrm{~m}$ and the corresponding power potential at $50 \mathrm{~m}$ height of the four classes of wind categories are depicted in Fig.5. In similar studies according to (Elhadidy, M.A. et al., 2005) in wind resource assessment of Eastern coastal region of Saudi Arabia, he said that Wind is faster, less turbulent and yields more energy at 50m or more heights above the ground. (Alam M. et al., 2011) Also investigates the wind speed increases with height in each class. Wind speed is increase with height. As the height of wind speed measurement increase, the percent frequency of occurrence of higher winds also increases.

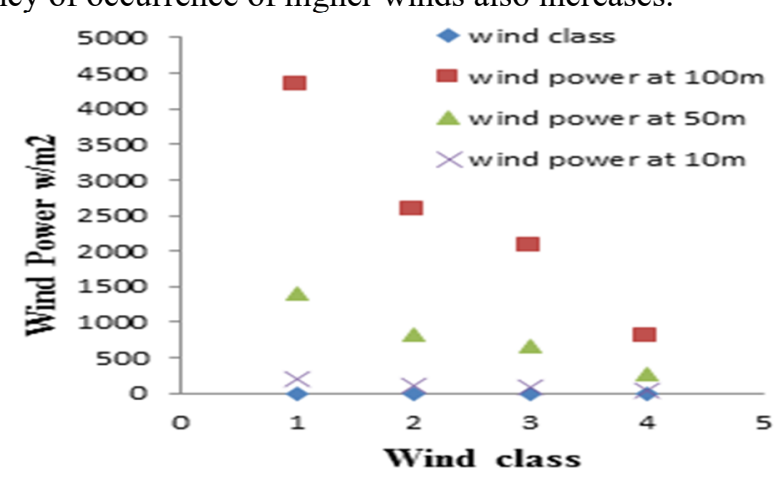

Fig 6: Wind power potential at 10, 50 and $100 \mathrm{~m}$.

Similarly, wind power potential increase with height as shown in Fig 5. The average wind power densities for summer are therefore $328 \mathrm{Wm}^{-2}, 190 \mathrm{Wm}^{-2}, 138 \mathrm{Wm}^{-2}$ and $52 \mathrm{Wm}^{-2}$ for winter are $17 \mathrm{Wm}^{-2}, 17 \mathrm{Wm}^{-2}, 12 \mathrm{Wm}^{-}$ ${ }^{2}$ and $12 \mathrm{Wm}^{-2}$ class 1 , class2, class 3 and class 4 respectively. The wind speed distributions show that summers have good wind distributions with $>294 \mathrm{~W} \mathrm{~m}^{-2}$ wind power densities. Although these methods are very vital for statistical analysis of observed wind data, mesoscale modeling provides a liberty to use the wind data at several key levels. According to (Dennis E., 2007) in wind resource assessment and mapping for Afganistan and Pakistan, he found similar results in wind power classification. He also included in calculations by assuming installed capacity per $\mathrm{km}^{2}=5 \mathrm{MW}$ at $50 \mathrm{~m}$ height. 
Table 2: Super to Good wind resource. Wind resource capacity calculated at 50 and $100 \mathrm{~m}$

\begin{tabular}{|l|l|l|l|l|l|l|l|l|}
\hline Rating & $\begin{array}{l}\text { Wind } \\
\text { class }\end{array}$ & $\begin{array}{l}\text { Wind } \\
\text { Speed at } \\
50 \\
(\mathrm{~m} / \mathrm{s})\end{array}$ & $\begin{array}{l}\text { Wind } \\
\text { Speed at } \\
100 \mathrm{~m} \\
(\mathrm{~m} / \mathrm{s})\end{array}$ & $\begin{array}{l}\text { Wind } \\
\text { Power at } \\
50 \mathrm{~m} \mathrm{~W} / \mathrm{m}^{2}\end{array}$ & $\begin{array}{l}\text { Wind } \\
\text { Power at } \\
100 \mathrm{~m} / \mathrm{m}^{2}\end{array}$ & $\begin{array}{l}\text { Land } \\
\text { area } \\
\left(\mathrm{Km}^{2}\right)\end{array}$ & $\begin{array}{l}\% \text { of } \\
\text { windy } \\
\text { Land }\end{array}$ & $\begin{array}{l}\text { Total } \\
\text { capacity at } \\
100 \mathrm{~m}(\mathrm{MW})\end{array}$ \\
\hline Super & 1 & 10.39 & 15.8 & 1392 & 4331 & 159 & 0.25 & 794 \\
\hline Outstanding & 2 & 8.75 & 13.3 & 830 & 2583 & 318 & 0.5 & 1,590 \\
\hline Excellent & 3 & 8.13 & 12.36 & 665 & 2073 & 477 & 0.75 & 2,385 \\
\hline Good & 4 & 5.95 & 9.04 & 261 & 811 & 1,112 & 1.75 & 5,560 \\
\hline Total & & & & & & 2,066 & 3.25 & 10,329 \\
\hline
\end{tabular}

\subsection{Total wind power density distribution over Bale zone.}

To estimate the wind power densities across the Bale zone wind speed distributions at 50 and $100 \mathrm{~m}$ were used. These vertical heights are key levels as most of the wind turbine hub heights are planted around those level values. The moist air density at 50 and $100 \mathrm{~m}$ is $1.013 \mathrm{~kg} \mathrm{~m}^{3}$ and $0.912 \mathrm{~kg} \mathrm{~m}^{3}$ respectively based on Eqn. 5 first by extracting the temperature, pressure and mixing ratio from the WRF model. Then by using Eqn 4 wind power density at 100 $\mathrm{m}$ is calculated and the estimation result is given in Table2.

Assumptions to calculate the installed capacity per km² $=5 \mathrm{MW}$ (Frank, 2014)

Total land area of Bale zone $=63,555 \mathrm{~km}^{2}$

Good to Excellent wind resource is 2,066 sq. km almost $3.25 \%$ of Bale zone's total land area of $63,555 \mathrm{sq}$. $\mathrm{km}$. 10,329 MW of potential installed wind capacity assumes $5 \mathrm{MW}$ per sq. km. And also according to (Manwell F., et al., 2009) the installed capacity per $\mathrm{km}^{2}$ is $5 \mathrm{MW}$.

The average wind power density (Figure 6) is calculated for the (class 1, class 2, class 3 and class 4 ) the results are 4331, 2583, 2073 and $811 \mathrm{~W} / \mathrm{m}^{2}$ at $100 \mathrm{~m}$ vertical heights and 1392, 830, 665 and $261 \mathrm{~W} / \mathrm{m}^{2}$ for the 50 $\mathrm{m}$ vertical heights respectively. The result shows that wind power density increases with height.

\subsection{The difference between the observed and simulated wind data}

The simulated WRF model output and observational ground meteorological wind data are shown in Fig. 7. As shown in the figure the first one is the wind speed from simulated data and observational data. From the result there is a little bias. In general WRF configured with high resolution in space and time predicts accurately wind speeds over Bale zone. While the work performed was a good representative of the year, more simulations and observations are required to draw a complete confidence level of wind profiles over the study area

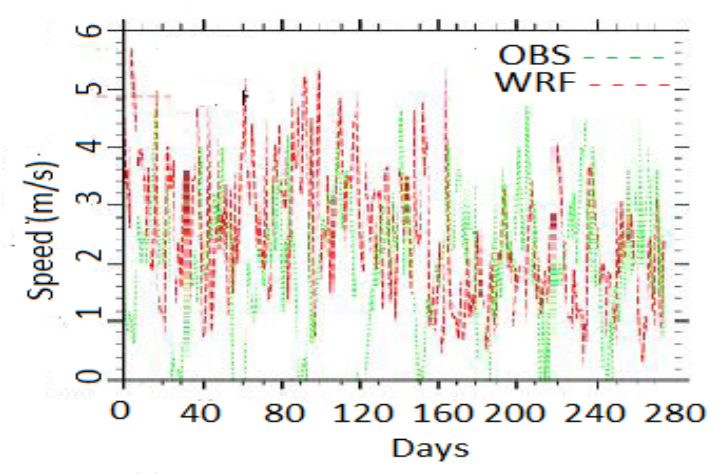

(a)

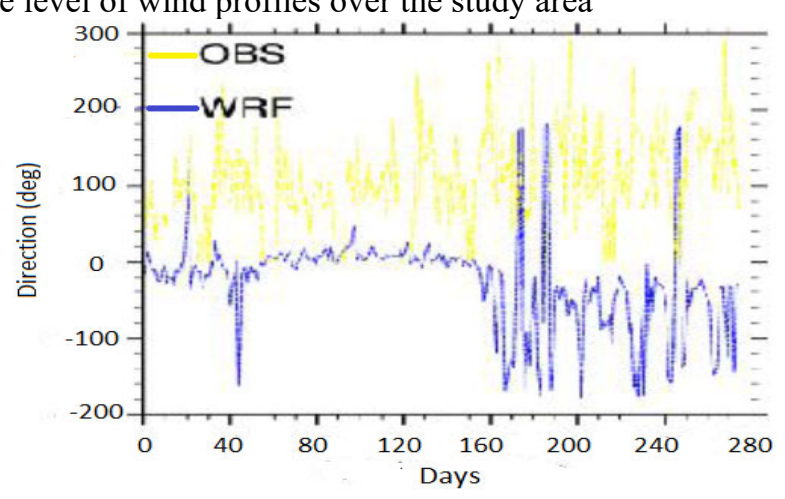

(b)

Fig.7 Comparison between observational and WRF model wind speed (a) and wind direction (b).

\subsection{Environmental Analysis}

Environmental conservation have economic benefits by Providing raw materials such as land, water, minerals and timber for economic production and consumption, income and employment; Generating ecological services such as pollution regulation, climate control and water catchment protection which protect natural and human resources through providing a sink for wastes and residues and maintaining essential life support functions; Giving aesthetic pleasure and holding cultural significance for many different people.

For this study the emission saved (other than carbon) from wood, charcoal and kerosene, controlling pollution by the proper use of slurry, minimization of indoor pollution due to the use of traditional fuels and the decrease of women's load are considered to be intangible, but highly rewarding. The tangible benefits are presented below.

\subsubsection{Decrease in deforestation}

Deforestation, clearance, or clearing is the removal of a forest or stand of trees where the land is thereafter converted to a non-forest use (SAF net Dictionary, 2008). Deforestation occurs for multiple reasons: trees are cut 
down to be used for building or sold as fuel (sometimes in the form of charcoal or timber), while cleared land is used as pasture for livestock and plantation.

The removal of trees without sufficient reforestation has resulted in habitat damage, biodiversity loss and aridity. It has adverse impact on bio sequestration of atmospheric carbon dioxide. As of 2005, net deforestation rates have ceased to increase in countries with a per capita GDP of at least US\$4,600 (Kauppi, P. E. et al., 2006; The New York Times, 2009). Deforested regions typically incur significant adverse soil erosion and frequently degrade into wasteland. Deforestation causes extinction, changes to climatic conditions, desertification, and displacement of populations as observed by current conditions and in the past through the fossil record (Sahney, S., 2010).

This study reveals that because of huge potential wind resource in south eastern Ethiopia deforestation will be reduced. The amount of fire wood will be saved when introduce wind energy estimated and the equivalent number of trees was calculated using literature value i.e. $712 \mathrm{~kg}$ of dry wood is equivalent to 6 large trees (USDA forest service 2010), and to produce $1 \mathrm{~kg}$ of charcoal $5.21 \mathrm{~kg}$ of wood are required (Sepp 2014). Thus using 6 trees $/ 712 \mathrm{~kg}$ of wood and $1 \mathrm{kgcharcoal} / 5.21 \mathrm{~kg}$ of wood as conversion factors, and estimating the total wind energy users into consideration, the yearly decline in deforestation is estimated and showed in Table 3.

Table 3. Annual deforestation decline rate

Source: Survey data

\begin{tabular}{|l|l|l|l|}
\hline \multirow{2}{*}{} & \multicolumn{3}{|c|}{ Annual deforestation decline rate } \\
\cline { 2 - 4 } & Fire wood & Charcoal & Save forest \\
\hline Percentage & 59 & 68 & 65 \\
\hline
\end{tabular}

\subsubsection{Emission saving}

A healthy tree stores up to 13 pounds $(6 \mathrm{~kg})$ of carbon annually (USDA forest service 2010; Nowak and Crane 2002). Table 3 indicates that $65 \%(10,549)$ trees will be saved annually due to wind energy dissemination in South Eastern Ethiopia if replacing some part of the fire wood and charcoal by wind energy. Besides the carbon saved, which otherwise would be released when cutting trees, about $66294 \mathrm{~kg}$ of carbon is stored per year.

\section{CONCLUSION}

In this study wind reanalysis and station metrological wind speed and direction data were analyzed to assess the wind resource potential of Bale zone. The wind speed and wind speed potential increase with altitude and summer has very good wind potential than winter season. From the five months of April, May, June, July and August the wind speed statistics based on the $10 \mathrm{~m}$ model wind speed and direction output showed a high wind potential in June and low in November. September and March are transition months for most of the Bale zone district. The month of November also shows the lowest wind speed from winter seasons of October, November, December, January and February.

The 2D distribution of the $10 \mathrm{~m}$ wind speed output during June, wind speed distributions of the Bale zone area showed high winds while the low elevations and valleys showed relatively low wind speeds. This will depend on many factors including but not limited to proximity to grid connection, access to area, and land use and land cover among others. In similar studies (E Streevalson, 2009) the crest of hills, cliffs, ridges and escarpments, the wind accelerate while near the foot and valley it will decelerate. And also according to (Lebassi B. et al., 2013) in wind resource assessment in Dragash-Kosovo he found that the wind close to the low level jet have higher wind resources since they get momentum transfer from the jet by eddy mixing. The valleys are relatively low wind speeds due to winds tipped in the jet toward the hill. The 50 and $100 \mathrm{~m}$ wind distributions also analyzed which showed higher wind speeds with similar pattern as expected. The wind power densities of the two heights showed similar patterns as the distribution of wind speeds where the high and medium elevations showed the high wind power densities.

The tropical areas of bale zone relatively have high wind power density. From the Bale zone east plain region mainly Dawekachen, Rayitu, Sewena, Beltu and Medawelabu districts are the areas with super to outstanding wind potential and Daweserer, Gololcha, Delosebro, Maliyu, Goba, Sinana and Robe town have the excellent to good wind potential area when compared with the others. This study showed that most of the Bale zone areas have significant wind power potential to augment its current power generation. Mean wind speed of Bale zone in east is higher than west and southwest wind shares higher in direction distribution. This indicates southeast of Bale zone is highly influenced by low level jet from Somalia. Hence it's richest in wind energy resource reserve in Bale zone. Therefore it meets requirements for assessing macro wind energy resource in most area over the Bale zone. Have a potential of installed 10,329MW wind capacity in Bale zone. If this potential wind resource will installed and only $10 \%$ of the population is used, so far environment as an estimation of about more than 5 thousand hectare of forest land per year would be preserved, and subsequently, equivalent amount of about 66,294 of $\mathrm{CO}_{2}$ would be stored per year. In this study area due to lack of observational data, microscale wind modeling is challenging to accurately reproduce for any location in the area. 


\section{Recommendations}

Based on the empirical findings of this study, we forward the following recommendations.

To found more accurate result it is necessary to increase spacial resolution and long term analysis is required for better results. Based stations are sparsely distributed. Thus more measurements are necessary to acquire temporally high resolution meteorological data at key locations in the area. But we feel that these findings are good starting points for further study to choose optimal wind resource site in Bale zone.

\section{Acknowledgements}

We would like to extend our heartfelt thanks to Madawalabu University Research and Community service Directorate for providing financial support. Ethiopian Metrological Service (NMA) and National Centers for Environmental Prediction (NCEP) Final (FNL) Operational Global Analysis data for providing the data free of charge.

\section{References}

Alam M., Shafiqur R., Josua M., Luai M. and Al-Hadhrami, (2011). Wind speed and power characteristics at different heights for a wind data collection tower in Saudi Arabia, World renewable energy congress, Sweden.

Antonio C., Guido C., Hans E. and René S. (1997). Vertical profiles of wind, temperature and turbulence, COST Action 710 Preprocessing of Meteorological Data for Dispersion Modelling Report of Working Group3.

AshenafiAbebe, GelanaAmente and GetachewAbebe, (2008). Short-Term Temporal Wind Speed Variability: Case Study of Dubbo Village, Journal of Chemical, Biological and Physical Sciences, an International Peer Review E-3 Journal of Sciences.

BZFEDO (Bale Zone Finance and Economic Development Office). (2013). Bale, Robe.

Clifford, Kevin Thomas. (2011). WRF-Model Performance for Wind Power Forecasting in the Coast Ranges of Central California, Master's Theses Paper 4043.

Dennis E., (2007). Wind Resource Assessment and Mapping for Afghanistan and Pakistan, National Renewable Energy Laboratory Golden, Colorado USA.

Derbew Derese (2013). Ethiopia's Renewable Energy Power Potential and Development Opportunities, Ministry of Water and Energy, Abu Dhabi.

E. Streevalsan, (2009). Wind resource and assessment techniques. International Journal of wind and Renewable Energy Volume 3.

Elhadidy, M.A. and Shaahid, S.M., (2005). Wind Resource Assessment of Eastern Coastal Region of Saudi Arabia, Journal of the Association of Arab Universities for Basic and Applied Sciences, Vol. 1, 2005, 1-14.

F. J. Santos-Alamillos. (2013). Analysis of WRF Model Wind Estimate Sensitivity to Physics Parameterization. http://journals.ametsoc.org/doi/abs/10.1175/JAMC-D-12-0204.1, Published Online: 13 July.

Frank Kreith, Susan Krumdieck (2014). Principles of Sustainable energy Systems. second edition, CRS Press, Taylor \& Francis Group.

J. J. Gómez-Navarro, C. C. Raible1, and S. Dierer. (2015). Sensitivity of the WRF model to PBL parameterizations and nesting techniques: evaluation of wind storms over complex terrain. Geosci Model Dev, 8, 3349-3363.

Jimenez, P. A., J. Dudhia, J. F. Gonzalez-Rouco, J. P. Montavez, E. Garcia-Bustamante, J. Navarro, J. Vila-Guerau de Arellano, and A. Munoz-Roldan. (2013). An evaluation of WRF's ability to reproduce the surface wind over complex terrain based on typical circulation patterns, J. Geophys. Res. Atmos., 118, 7651-7669, doi:10.1002/jgrd.50585.

Jowder F. (2009). Wind power analysis and site matching on wind Turbine generators in Kingdom of Bahrain, Applied Energy.

Karimiotakis P., Pinson K. and Giebel G. (2004). The state or art in short-term prediction of wind power-from an offshore perspective. Sea Technology Week, France.1-13.

Kauppi, P. E.; Ausubel, J. H.; Fang, J.; Mather, A. S.; Sedjo, R. A.; Waggoner, P. E. (2006). Returning forests analyzed with the forest identity. Proceedings of the National Academy of Sciences. 103 (46): 17574

Lebassi, B., Berhane T. and Mengisteab A., (2013). Wind Resource Assessment in Dragash - Kosovo, United Nations Development Programme.

Ma Y., Huang M. and Mills G. (2009). Verification of mesoscale NWP forecasts of abrupt cold frontal wind changes. Weather and Forecasting, volume 25.

Manwell F., McGowan J. and Rogers A. (2009). Wind Energy Explained: Theory, Design and Applications, 2nd Edition, A John Willey and Sons, Ltd. Publications.

McKnight, Tom L; Hess, Darrel (2000). Climate Zones and Types: The Koppen System. Physical Geography: A Landscape Appreciation. Upper Saddle River, NJ: Prentice Hall, pg. 208, ISBN 0-13-020263-0.

Nowak, DJ., Crane, DE. (2002). Carbon storage and sequestration by urban trees in the USA. Environmental pollution. 116:381-389

Oumer, (2013). Wind Resource Data Analysis: The case of Myderhu project site, Tigray regional state, Ethiopia, 
KTH School of Industrial Engineering and Management Energy Technology EGI-2013-051MSC EKV953 Division of Heat \& Power SE-100 44 Stockholm 051msc ekv953.

Pryor S. and Barthelmie R. (2011). Assessing climate change impacts on the near-term stability of the wind energy resource over the United States. Proc Nati Acad Sci (PNAS) U S A., May 17; 108(20): 8167-8171.

Ritter, Michael E. (2006). The Physical Environment, an Introduction to Physical Geography.

SAFnet Dictionary Definition For deforestation. Dictionary of forestry.org (29 July 2008). Retrieved 2011-05-15.

Sahney, S., Benton, M.J. \& Falcon-Lang, H.J. (2010). Rainforest collapse triggered Pennsylvanian tetrapod diversification in Euramerica. Geology. 38 (12): 1079-1082. Bibcode:2010Geo....38.1079S. doi:10.1130/G31182.1

Skamarock W. and Coauthors C. A. (2008). Description of the Advanced Research WRF Version 3, MMM division, NCAR Technical Note, NCAR/TN-475+STR.

T. Haghroosta, W. R. Ismail P. Ghafarian, and S. M. Barekati. (2014). The efficiency of the Weather Research and Forecasting (WRF) model for simulating typhoons. Nat. Hazards Earth Syst. Sci., 14, 2179-2187.

The New York Times, (2009). Use Energy, Get Rich and Save the Planet, The New York Times, 20 April 2009. USDA forest service, (2010). Assessing Urban Forest Effects and Values. Chicago's Urban Forest. 